\title{
Active accumulation of internal DIC pools reduces transport limitation in large colonies of Nostoc pruniforme
}

\author{
A. L. Raun*, J. Borum, K. Sand-Jensen \\ Freshwater Biological Laboratory, University of Copenhagen, Helsingørsgade 51, 3400 Hillerød, Denmark
}

\begin{abstract}
Nostoc pruniforme is a freshwater cyanobacterium forming large spherical colonies of up to several centimeters in diameter. The size and shape result in low surface area to volume (SA/V) ratios that potentially put severe constraints on resource acquisition. In the present study we have specifically examined how $N$. pruniforme copes with the acquisition of dissolved inorganic carbon (DIC) for photosynthesis. The results showed that $N$. pruniforme elevates its functional SA/V considerably by locating the cyanobacterial trichomes primarily in the outer shell, while the inner mucus of polysaccharides contains declining densities of trichomes with increasing colony size. $N$. pruniforme is a very efficient bicarbonate $\left(\mathrm{HCO}_{3}{ }^{-}\right)$user and, in addition, actively accumulates large pools of DIC that can support net photosynthesis for $>22 \mathrm{~h}$ without a supply of external DIC. Both the efficient $\mathrm{HCO}_{3}{ }^{-}$utilization and the large internal DIC pools greatly reduce $N$. pruniforme dependence on the immediate availability and species of external DIC. The location of the trichomes in the shell, the $\mathrm{HCO}_{3}{ }^{-}$utilization and the internal DIC pools mean that colony size only has a minor effect on photosynthetic rates as a function of external DIC availability.
\end{abstract}

KEY WORDS: Nostoc pruniforme - Inorganic carbon acquisition · DIC accumulation · Bicarbonate use $\cdot$ Colony size $\cdot$ Photosynthesis

Resale or republication not permitted without written consent of the publisher

\section{INTRODUCTION}

Nostoc pruniforme C. Agardh ex Bornet \& Flahault is a freshwater cyanobacterium forming macroscopic, spherical colonies that may reach $>10 \mathrm{~cm}$ in diameter (Dodds \& Castenholz 1988, Dodds et al. 1995). The colonies are attached to the bottom substrata or lie loosely on the sediment in oligotrophic, low-alkaline lakes as well as in more eutrophic alkaline lakes (Dodds et al. 1995). Although colonies are most often only 0.1 to $1.5 \mathrm{~cm}$ in diameter, the large spherical form offers unfavorably low surface area to volume ratios $(\mathrm{SA} / \mathrm{V})$ that may restrict the supply of inorganic carbon, nutrients and light for photosynthesis and growth.

The sphere has the lowest SA/V of all geometric forms. Many microalgae are spherical, but, due to their small size, maintain SA/V values $>10000 \mathrm{~m}^{-1}$, which allow high rates of inorganic carbon and nutrient ex- change with the external medium, as well as efficient light harvesting (Raven \& Kübler 2002). Since the SA/V is inversely related to the linear dimension, most larger colonies and macrophytes change form and become filamentous or flat to maintain sufficient surface area for resource acquisition (Littler \& Littler 1980). However, a few colonial algae, cyanobacteria (e.g. Nostoc spp.) and macroalgae (e.g. Codium spp.) maintain their spherical form and therefore experience challenging constraints on acquisition of resources for photosynthesis and growth. In the present study we specifically examined how $N$. pruniforme copes with the acquisition of dissolved inorganic carbon (DIC) for photosynthesis.

There are potentially several ways for spherical autotrophs to ameliorate the constraints on inorganic carbon supply at low SA/V ratios. Nostoc pruniforme consists of unbranched trichomes embedded in a firm surface pellicle (shell) and a gelatinous interior (mu- 
cus) of polysaccharides (Dodds et al. 1995). Since light absorption is high $(>90 \%$ is attenuated within the outer $100 \mu \mathrm{m}$ of the colony surface of $N$. parmelioides; Dodds et al. 1995), the most obvious adaptation to deal with the low SA/V is to concentrate the trichomes in the outer shell and reduce the density of trichomes in the interior mucus with increasing colony size and, thereby, functionally elevate the SA/V and reduce distance to the external DIC source. The low SA/V can, in part, also be compensated for by optimizing inorganic carbon uptake and developing storage strategies. Inorganic carbon acquisition in $N$. pruniforme has, to our knowledge, not yet been subjected to detailed studies, but it can be expected that $N$. pruniforme, like most other cyanobacteria, has an efficient bicarbonate $\left(\mathrm{HCO}_{3}{ }^{-}\right)$utilization (Kaplan et al. 1980, Sültemeyer et al. 1998, Beer et al. 1990). Like other cyanobacteria, Nostoc spp. may also have inorganic carbonconcentrating mechanisms that allow accumulation of very high internal pools of DIC (Kaplan et al. 1980, Badger \& Price 1992).

The isotopic carbon composition of Nostoc pruniforme shows that $\delta^{13} \mathrm{C}$ is highly enriched relative to that of free $\mathrm{CO}_{2}$, suggesting $\mathrm{HCO}_{3}{ }^{-}$utilization, and low seasonal variability in $\delta^{13} \mathrm{C}$ may reflect the existence of large internal pools of DIC (Goericke et al. 1994, Finlay 2004). Both mechanisms would make $N$. pruniforme less dependent on the immediate availability of free $\mathrm{CO}_{2}$, and internal DIC pools would offset any limitation due to constraints on DIC uptake at high photosynthesis during the day.

Our aim was to examine to what extent Nostoc pruniforme can cope with the potential constraints on inorganic carbon acquisition imposed by its low SA/V. We examined the spatial distribution of trichomes inside colonies of increasing size. We measured colony photosynthesis as a function of free $\mathrm{CO}_{2}$ to determine maximum rates of photosynthesis and to quantify rates when no external free $\mathrm{CO}_{2}$ is available and, thereby, evaluate the ability of $N$. pruniforme to use external $\mathrm{HCO}_{3}{ }^{-}$or exploit internal DIC pools. Bicarbonate utilization was specifically tested by $\mathrm{pH}$-drift experiments, and the existence of an effective inorganic carbon-concentrating mechanism that would allow accumulation of large DIC pools within the colonies was examined in experiments with no external DIC. Finally, we measured photosynthesis as a function of colony size and external DIC to evaluate whether inorganic carbon acquisition changes systematically with $\mathrm{SA} / \mathrm{V}$. If $N$. pruniforme trichomes are primarily found in the colony shell and if $N$. pruniforme exhibits efficient $\mathrm{HCO}_{3}^{-}$utilization and has strong inorganic carbon-concentrating mechanisms, its photosynthesis should be relatively independent of the immediate availability of inorganic carbon in the water.

\section{MATERIALS AND METHODS}

Nostoc pruniforme colonies of different sizes were sampled in late summer and autumn in shallow water in the eutrophic, temperate Lake Esrum, Denmark $\left(56^{\circ} 02.09^{\prime} \mathrm{N}, 12^{\circ} 22.32^{\prime} \mathrm{E}\right)$. The lake is alkaline ( 2.2 to $2.7 \mathrm{mmol} \mathrm{DIC} \mathrm{l}^{-1}$ ), and the $\mathrm{pH}$ is usually between 8.0 and 8.5 , but reaches higher values during phytoplankton blooms. The colonies were rapidly transferred to the laboratory in lake water. If not immediately used for measurements, the colonies were kept in dim light $\left(<100 \mu \mathrm{E} \mathrm{m}^{-2} \mathrm{~s}^{-1}\right.$, PAR [photosynthetically active radiation], in a $16 \mathrm{~h}$ dark: $8 \mathrm{~h}$ light cycle) and at constant temperature $\left(16^{\circ} \mathrm{C}\right)$ in aquaria without sediment. The water was aerated and gently stirred by bubbling with atmospheric air. Time from sampling to measurements never exceeded $3 \mathrm{wk}$.

To determine the distribution of trichomes within colonies of different sizes, chlorophyll a (chl a) was extracted from the firm surface pellicle and the interior mucus of freshly collected colonies. The colonies were cut in half, and the interior mucus was gently separated from the outer shell with a scalpel. Shell and mucus were freeze dried for $24 \mathrm{~h}$, and dry weight was determined before extraction of chl $a$ in $96 \%$ ethanol according to Wintermans \& DeMots (1965).

Photosynthesis was measured on freshly collected colonies exposed to constant irradiance $\left(610 \mu \mathrm{E} \mathrm{m}{ }^{-2} \mathrm{~s}^{-1}\right.$, PAR) and DIC ( $\left.0.88 \mathrm{mmol} \mathrm{l}^{-1}\right)$, but to different availabilities of free $\mathrm{CO}_{2}$ by manipulating $\mathrm{pH}$. The experimental medium was a mixture of water from Lake Esrum (1/3) and demineralized water $(2 / 3)$ in order to reduce DIC and minimize the amounts of acid needed for $\mathrm{pH}$ manipulations. Initially, the $\mathrm{pH}$ was raised to 9.5 by adding $\mathrm{NaOH}$, and photosynthesis was measured as $\mathrm{O}_{2}$ production following stepwise reduction of $\mathrm{pH}$ with $\mathrm{HCl}$ until $\mathrm{pH} 5$.

The photosynthetic chamber $(0.17 \mathrm{l})$ was made of Perspex and closed with a lid allowing insertion of an $\mathrm{O}_{2}$ minielectrode (OX500; Unisense), a pH electrode and injection of acid. The chamber was submerged in a temperature-controlled bath $\left(16^{\circ} \mathrm{C}\right)$ and supplied with a magnetic stirrer. The $\mathrm{O}_{2}$ electrode was connected to a picoameter (PA2000; Unisense), and the signal was logged on a computer through an ADC16 converter (converter and software; Picolog). Before and after each series of measurements, the electrode was calibrated at $0 \% \mathrm{O}_{2}$ and at air equilibrium. Photosynthetic rates at different $\mathrm{pH}$ values were measured over periods of 3 to $5 \mathrm{~min}$, exhibiting linear increases in $\mathrm{O}_{2}$ concentration. During each period, $\mathrm{pH}$ changed by $<0.02$ units. Total DIC in the medium was measured by end-point titration (Stumm \& Morgan 1970) or by direct analysis with an ADC225 MK3 infrared gas analyzer (IRGA; Analytical Development Co.). 
Concentrations of free $\mathrm{CO}_{2}$ and $\mathrm{HCO}_{3}{ }^{-}$were calculated from alkalinity, temperature and conductivity according to Mackereth et al. (1978). Photosynthetic rates versus concentrations of free $\mathrm{CO}_{2}$ were fitted to the Michaelis-Menten equation, modified by adding a constant representing the $y$-axis intercept.

The ability of Nostoc pruniforme to take up $\mathrm{HCO}_{3}^{-}$ was tested in $\mathrm{pH}$-drift experiments, in which colonies were allowed to photosynthesize in closed bottles for up to $24 \mathrm{~h}$ until carbon fixation ceased because of DIC limitation at high pH (Allen \& Spence 1981, Maberly \& Spence 1983). The incubation water was a mixture of lake and demineralized water resulting in a DIC concentration of $0.57 \mathrm{mmol} \mathrm{l}^{-1}$, and the bottles were mounted on a rotating wheel in a cooling bath maintained at $16^{\circ} \mathrm{C}$. The colonies were exposed to constant irradiance of $485 \mu \mathrm{E} \mathrm{m} \mathrm{m}^{-2} \mathrm{~s}^{-1}$ (PAR). When the $\mathrm{pH}$ increase ceased, the end $\mathrm{pH}$ was recorded and total DIC was measured on the IRGA.

Internal DIC pools within freshly collected Nostoc pruniforme colonies were determined immediately after sampling. Each colony was incubated in demineralized water that had been bubbled with $\mathrm{N}_{2}$ for at least 45 min to remove virtually all DIC and $\mathrm{O}_{2}$. DIC was low

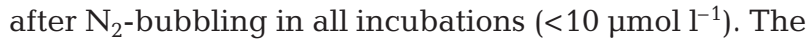
colonies were allowed to photosynthesize under constant irradiance $\left(610 \mu \mathrm{E} \mathrm{m}^{-2} \mathrm{~s}^{-1}, \mathrm{PAR}\right)$ and temperature $\left(16^{\circ} \mathrm{C}\right)$ until photosynthesis ceased due to exhaustion of the DIC pool. The pools of internal DIC accumulated in excess of the concentration found in lake water $\left(2.2 \mathrm{mmol} \mathrm{l}^{-1}\right)$ were estimated from total $\mathrm{O}_{2}$ production assuming a photosynthetic quotient of 1.0.

To test whether the internal DIC pools were the result of an active concentrating mechanism or high DIC diffusion from the sediment into the colonies, internal pools of DIC were estimated in colonies after $12 \mathrm{~d}$ of incubation in enclosures with and without direct sediment contact in the lake. Colonies of approximately the same size (ca. $1.5 \mathrm{~cm}$ in diameter) were sampled and transferred to polyethylene buckets with or without a bottom. The buckets were covered with $1 \mathrm{~cm}$ mesh size nets to enclose the colonies. After harvest, the colonies were brought to the laboratory and incubated individually $(\mathrm{n}=7$ ) in closed glass bottles with a mixture of $\mathrm{N}_{2}$-bubbled lake and demineralized water $(0.31 \mathrm{mmol}$ $\mathrm{DIC}^{-1}, \mathrm{pH}$ 7.06) of known $\mathrm{O}_{2}$ concentration. The bottles were mounted on a rotating wheel in a cooling bath at $16^{\circ} \mathrm{C}$ and saturating irradiance of $485 \mu \mathrm{E} \mathrm{m} \mathrm{m}^{-2} \mathrm{~s}^{-1}$ (PAR). After $18 \mathrm{~h}$ of incubation, $\mathrm{O}_{2}$ concentration was measured with a minielectrode, and DIC with an IRGA. The DIC stored inside the colonies was calculated as total $\mathrm{O}_{2}$ production (assuming a photosynthetic quotient of 1) minus the DIC extracted from the water.

A final experiment was conducted to examine how photosynthesis in colonies of different size depended on DIC concentrations. Colonies that had been stored for several days in lake water in dim light were incubated in closed glass bottles with mixtures of lake and demineralized water to create a range of DIC levels from close to 0 to $2.6 \mathrm{mmol}^{-1}$. Colony sizes were about $0.18,0.84$ and $2.71 \mathrm{~g}$ wet weight, corresponding to diameters of 7,12 and $17 \mathrm{~mm}$, respectively ( $\mathrm{n}=3$ for each size class). The bottles were mounted on a rotating wheel as described above, and $\mathrm{O}_{2}$ evolution was measured after $2 \mathrm{~h}$ of incubation. The relationship between photosynthetic rates and initial DIC was fitted to the modified Michaelis-Menten equation as described above to compare $K_{\mathrm{m}}$ and $V_{\max }$ for the differently sized colonies.

\section{RESULTS}

The cyanobacterial trichomes were clearly more concentrated in the outer shell of Nostoc pruniforme colonies, since the chl a concentrations here were 5- to 10-fold higher per gram wet weight than in the interior mucus (Fig. 1). There was no systematic change in shell chlorophyll concentration with increasing colony size ( $p=0.61, t$-test), while the interior chlorophyll concentration declined significantly ( $p<0.0001)$.

The photosynthetic rate of freshly collected colonies at constant DIC $\left(0.883 \mathrm{mmol} \mathrm{l}^{-1}\right)$, but variable free $\mathrm{CO}_{2}$, could be described by modified Michaelis-Menten kinetics (Fig. 2). Photosynthesis estimated at 'zero' free $\mathrm{CO}_{2}$ (y-axis intercept) was $37 \pm 9 \mu \mathrm{mol} \mathrm{O}_{2} \mathrm{mg}^{-1} \mathrm{chl} \mathrm{a}$ $\mathrm{h}^{-1}$ (mean $\pm 95 \%$ CL [confidence limit], $\mathrm{n}=4$ ), corresponding to $56 \%$ of $V_{\max }\left(66 \mu \mathrm{mol} \mathrm{O} \mathrm{mg}^{-1} \mathrm{chl} \mathrm{a} \mathrm{h}^{-1}\right)$. $K_{\mathrm{m}}$ was $0.12 \mathrm{mmol}$ free $\mathrm{CO}_{2} \mathrm{l}^{-1}$, and $\mathrm{CO}_{2}$ saturated photosynthesis was reached at around $0.3 \mathrm{mmol} \mathrm{l}^{-1}$.

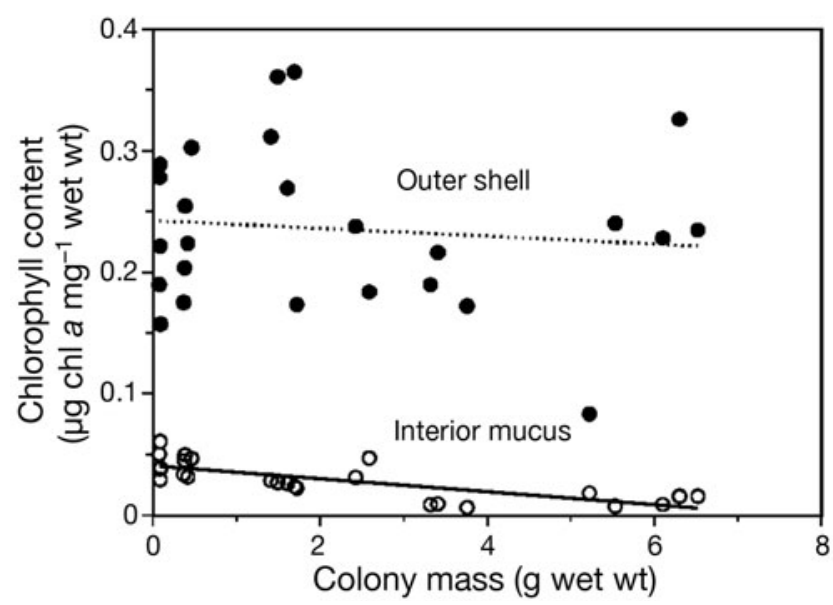

Fig. 1. Nostoc pruniforme. Chlorophyll a concentration per milligram wet weight in the outer shell and the interior mucus. The chlorophyll concentration did not change systematically with colony size in the outer shell, but declined significantly with colony size in the mucus (slope $=-0.0055, \mathrm{p}<0.0001$ ) 


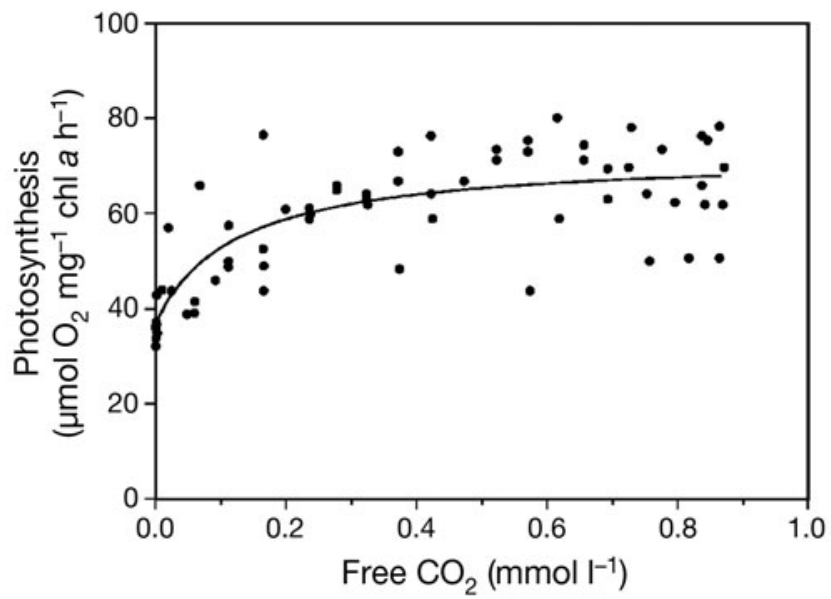

Fig. 2. Nostoc pruniforme. Photosynthesis of N. pruniforme versus availability of free $\mathrm{CO}_{2}$ changed by manipulating $\mathrm{pH}$ in water with constant dissolved inorganic carbon $\left(0.883 \mathrm{mmol} \mathrm{l}^{-1}\right)$. When fitted to a modified Michaelis-Menten equation, the photosynthetic rate at 'zero' free $\mathrm{CO}_{2}$ was $56 \%$ of $V_{\max }$ and the estimated $K_{\mathrm{m}}$ was $0.12 \mathrm{mmol} \mathrm{CO}_{2} \mathrm{l}^{-1}$

The pH-drift experiment showed a high ability of Nostoc pruniforme to utilize $\mathrm{HCO}_{3}{ }^{-}$. The $\mathrm{pH}$ increased from 8.5 to $10.4 \pm 0.2($ mean $\pm 95 \% \mathrm{CL}, \mathrm{n}=5)$, and the

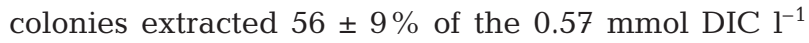
present at the start of the experiment during the $24 \mathrm{~h}$ incubations. At pH 10.4, free $\mathrm{CO}_{2}$ was $<0.03 \mu \mathrm{mol} \mathrm{l}^{-1}$.

Colonies incubated in almost DIC-free water maintained net photosynthesis based on internally accumulated DIC for 22 to $37 \mathrm{~h}$, although at decreasing rates. The estimated internal pools of inorganic carbon in the colonies were $6.1 \pm 1.5 \mathrm{mmol} \mathrm{DIC}^{-1}($ mean $\pm 95 \% \mathrm{CL}$ ) or $3.9 \pm 1.5 \mathrm{mmol} \mathrm{l}^{-1}$ above lake-water DIC.

The internal DIC pools accumulated in excess of the DIC in the water column were not just a result of high DIC diffusing passively from the sediment, but the result of active accumulation of DIC from the lake water. Colonies incubated in the lake with direct sediment contact had internal DIC pools of $8.67 \pm$ $1.33 \mathrm{mmol} \mathrm{l}^{-1}$ (mean $\pm 95 \% \mathrm{CL}$ ), which was not significantly higher than the $8.57 \pm 0.84 \mathrm{mmol} \mathrm{l}^{-1}$ accumulated in colonies without sediment contact (Student's $t$-test, $\mathrm{p}>0.05$ ).

Photosynthesis of stored colonies of different size increased with increasing DIC between 0.016 and $2.6 \mathrm{mmol} \mathrm{l}^{-1}$ (Fig. 3). All 3 size classes exhibited net photosynthesis at the lowest external DIC concentration based on use of internal DIC. The small- $(7 \mathrm{~mm}$ diameter) and medium-sized (12 $\mathrm{mm})$ colonies showed clear saturation kinetics, with maximum rates attained above $1.5 \mathrm{mmol} \mathrm{DIC} \mathrm{l}^{-1}$, while photosynthesis of the largest colonies $(17 \mathrm{~mm})$ was not saturated at the highest DIC level $\left(2.6 \mathrm{mmol} \mathrm{l}^{-1}\right)$. Net photosynthesis was not significantly different among colony sizes at differ-

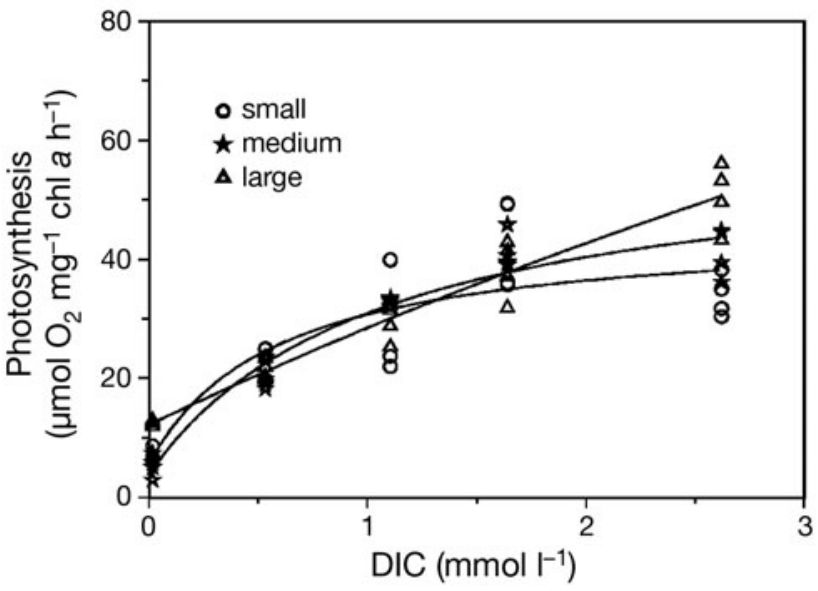

Fig. 3. Nostoc pruniforme. Photosynthesis of differently sized colonies versus total dissolved inorganic carbon (DIC). Small( $7 \mathrm{~mm}$ diameter) and medium-sized $(12 \mathrm{~mm}$ ) colonies exhibited clear saturation patterns, while large $(17 \mathrm{~mm})$ colonies showed no tendencies to saturate within the experimental range from 0 to $2.6 \mathrm{mmol} \mathrm{DIC}^{-1}(\mathrm{n}=4)$

ent DIC levels, except for large colonies that had significantly higher photosynthetic rates than the 2 other size classes at the lowest and the highest DIC concentrations ( $p<0.05$, Tukey test). The slope of photosynthesis as a function of increasing DIC concentration from 0 to $0.5 \mathrm{mmol} \mathrm{l}^{-1}$ was significantly steeper for the 2 smaller size categories of colonies than for the largest size group (linear regressions, $\mathrm{p}<0.05$ ). In the largest colonies, however, photosynthesis continued to increase linearly with external DIC concentrations up to $2.6 \mathrm{mmol} \mathrm{l}^{-1}$.

\section{DISCUSSION}

Nostoc pruniforme clearly elevated its functional $\mathrm{SA} / \mathrm{V}$ by localizing the cyanobacterial trichomes primarily in the outer shell of the colonies and reducing their density in the interior mucus. The ability of $N$. pruniforme to accumulate high concentrations of inorganic carbon within the colonies could potentially ensure sufficient DIC supply to trichomes in the interior mucus, but the high light attenuation in the outer shell creates a very unfavorable light climate inside the colonies (Dodds \& Castenholz 1988). Localization of the trichomes in the outer shell is, therefore, probably required to maximize light utilization rather than to maximize DIC acquisition. It is hard to imagine that trichomes in the mucus $>1 \mathrm{~cm}$ away from the surface will receive sufficient irradiance to exhibit net photosynthesis, and the few trichomes embedded there may survive by consuming polysaccharides from the mucus (Dodds et al. 1995). 
Freshly collected colonies of Nostoc pruniforme showed a remarkable ability to maintain high photosynthetic rates with almost no external DIC available $\left(<0.01 \mathrm{mmol} \mathrm{l}^{-1}\right)$. The estimated photosynthetic rate of freshly collected colonies was $56 \%$ of the maximum photosynthesis rate (Fig. 2), reflecting the use of accumulated high internal pools of DIC, as has been described for planktonic cyanobacteria (Kaplan et al. 1980, Badger \& Price 1992). Likewise, colonies of different size in water of negligible DIC (Fig. 3) released substantial amounts of dissolved oxygen, but at the highest rates from the largest colonies, perhaps reflecting a relatively larger internal DIC pool because of larger colony volume relative to the volume and pigment content of Nostoc spp. trichomes. Large internal DIC pools may also account for the lack of saturation kinetics of photosynthesis as a function of external DIC concentrations for the largest colonies in contrast to the smaller colonies (Fig. 3).

It is possible that the steeper initial slope of photosynthesis versus external DIC concentration in the range from 0 to $0.5 \mathrm{mmol}^{-1}$ of the 2 smallest colony size groups ( 7 and $12 \mathrm{~mm}$ diameter) compared to the largest size group (17 mm; Fig. 3) could be due to better diffusive supply of DIC through the thinner diffusive boundary layers in smaller compared to larger colonies. The size range is relatively narrow, however, which should restrict the size effect on diffusive limitation, but, in order to confirm its influence, direct determination of diffusive boundary layer dynamics is required. While the colony jelly is firm and without convective mass flow of solutes, complex diffusion processes of DIC may exist for both physical reasons, when turbulent eddies penetrate the diffusive boundary layer to the colony surface, and chemical reasons, because of complex gradients of $\mathrm{CO}_{3}{ }^{2-}, \mathrm{HCO}_{3}{ }^{-}, \mathrm{CO}_{2}$ and $\mathrm{pH}$ in the diffusive boundary layers at the colony surface as well as within the colonies and the imbedded Nostoc spp. trichomes. Transport dynamics of DIC cannot be unraveled as yet, due to lack of microelectrodes to measure $\mathrm{CO}_{2}, \mathrm{HCO}_{3}{ }^{-}$and DIC.

There is an additional uninvestigated size aspect related to the location of the colonies of Nostoc pruniforme on the lake sediments under natural conditions. Here, the smallest colonies are imbedded in the diffusive boundary layer overlying the sediment surface, while the largest colonies may in part protrude above it. This location may provide greater enrichment with solutes from decomposition in the sediment for small colonies, while thinner boundary layers and greater diffusive exchange with the lake water may exist for the larger colonies. When spherical colonies of $N$. parmelioides are located on inert rock substrata in streams, the situation is reversed, because the smallest colonies will have a disadvantage in terms of reduced nutrient supply from the stream water compared with larger colonies. Moreover, an observed shift from a spherical to an ear-shaped colony form extending into higher velocities above the stone surfaces is beneficial in terms of higher nutrient and DIC supply (Dodds 1989).

Nostoc pruniforme is indeed a very efficient $\mathrm{HCO}_{3}{ }^{-}$ user, as confirmed by the ability to drive $\mathrm{pH}$ to 10.4 while free $\mathrm{CO}_{2}$ is below $0.03 \mu \mathrm{mol} \mathrm{l} \mathrm{l}^{-1}$, and extracted

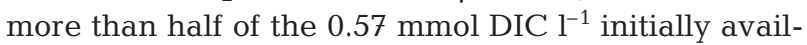
able. This is only possible for organisms that exhibit very efficient $\mathrm{HCO}_{3}{ }^{-}$uptake and utilization (Allen \& Spence 1981, Maberly \& Spence 1983). Efficient $\mathrm{HCO}_{3}{ }^{-}$-use is ecologically highly advantageous, because the availability of free $\mathrm{CO}_{2}$ is relatively low and quite variable in lakes (Madsen \& Sand-Jensen 1991).

Nostoc pruniforme was able to accumulate large internal DIC pools in excess of the concentrations in the lake water. These internal DIC pools could support net photosynthesis for $>22 \mathrm{~h}$ with no external DIC available (data not shown). The ability to accumulate large internal DIC pools and the efficient $\mathrm{HCO}_{3}{ }^{-}$utilization may allow $N$. pruniforme to ameliorate potential inorganic carbon limitation imposed by both its unfavorably low SA/V and low ambient DIC availability. These mechanisms probably explain why the species can grow in both low and high alkaline waters (Dodds et al. 1995).

The existence of large internal DIC pools agrees with observations of DIC accumulation and carbonconcentrating mechanisms in many planktonic and periphytic cyanobacteria (Kaplan et al. 1980, Beer et al. 1990, Badger \& Price 2003). In planktonic cyanobacteria, both $\mathrm{CO}_{2}$ and $\mathrm{HCO}_{3}{ }^{-}$are taken up actively by several uptake systems and stored in carboxysomes in the cytosol, after $\mathrm{CO}_{2}$ has been converted to $\mathrm{HCO}_{3}{ }^{-}$(Volokita et al. 1984, Price et al. 1992, Badger \& Price 2003). In the case of Nostoc pruniforme colonies, part of the internal DIC accumulation can, however, be derived from the mineralization of mucus leading to release of $\mathrm{CO}_{2}$. Because of the great longevity of colonies of $N$. pruniforme, we hypothesize that the mucus is relatively resistant to decomposition in order to maintain the colony structure and we suggest that this internal source of $\mathrm{CO}_{2}$ is small relative to uptake from the external medium. Respiratory release of $\mathrm{CO}_{2}$ from Nostoc spp. trichomes in the dark is, however, an important source of internal DIC accumulation in N. zetterstedtii, which is capable of retaining all respiratory DIC within the colony (Raun et al. 2008), and this mechanism may exist for $N$. pruniforme as well. $\mathrm{HCO}_{3}{ }^{-}$transport in cyanobacteria, in general, is regulated by external DIC availability, with low ambient DIC inducing fast uptake and transport (Sültemeyer et al. 1998). The $\mathrm{CO}_{2}$ concentrating mechanism is very efficient and may increase DIC levels 1000-fold around the active site of 
the carboxylating enzyme, Rubisco (Badger \& Price 2003). The edible, gelatinous Nostoc spp. colonies (GeXian-Mi) regarded as either $N$. commune or $N$. sphaeroides have multiple active transporters for $\mathrm{CO}_{2}$ and $\mathrm{HCO}_{3}{ }^{-}$in isolated algal filaments, but $\mathrm{Na}^{+}$-dependent $\mathrm{HCO}_{3}{ }^{-}$transport was the primary mode of DIC uptake supplying 53 to $63 \%$ of the net photosynthetic activity

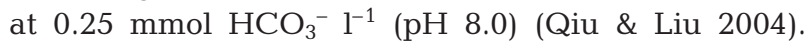
However, $\mathrm{CO}_{2}$-concentrating mechanisms are not present in all cyanobacterial species (Badger \& Price 2003), and their presence in $N$. pruniforme has, to our knowledge, never been examined before.

The observed DIC accumulation in Nostoc pruniforme was obviously due to a $\mathrm{CO}_{2}$-concentrating mechanism and not to high DIC concentrations diffusing from the sediment. Internal DIC concentrations in colonies of $N$. pruniforme were 3 to 4 times higher than lake water DIC values and, thus, far lower than the 1000 -fold increase around Rubisco reported by Badger \& Price (2003). However, if the internal DIC is confined to the algal trichomes, a very efficient $\mathrm{CO}_{2}$-concentrating mechanism is definitely required, since the trichomes occupy a relatively small proportion of the colonies.

There were only minor differences in photosynthetic response among size classes when pre-stored colonies of different sizes were exposed to DIC at different levels of availability (Fig. 3). The only clear difference was that photosynthetic rates of small- and medium-sized colonies saturated at lower DIC levels than in large colonies. This pattern is very different from the one described for Nostoc sphaeroides in rice paddies (Li \& Gao 2004). A DIC experiment with N. sphaeroides showed systematic and strong differences in the photosynthetic response with colony size. $V_{\max }$ declined markedly with increasing colony size, and $K_{\mathrm{m}}$ increased in agreement with what would be expected at declining SA/V (Li \& Gao 2004). We are not familiar with any differences in colony structure between the 2 Nostoc species, but, clearly, the low dependence on colony size of $N$. pruniforme must be explained by localization of the trichomes primarily in the outer shell and the efficient $\mathrm{HCO}_{3}{ }^{-}$utilization.

Our study suggests that the apparently unfavorably low surface area to volume ratio of Nostoc pruniforme for acquiring inorganic carbon is efficiently compensated for by localization of the trichomes in the outer shell, efficient $\mathrm{HCO}_{3}^{-}$utilization and the ability to accumulate substantial internal DIC pools through a $\mathrm{CO}_{2}$-concentrating mechanism. Nutrient acquisition may similarly be much more effective than could be expected from the low SA/V, and these findings may explain why $N$. pruniforme is found under both low and high alkaline conditions, in stagnant and flowing waters, and is an almost cosmopolitan species (Dodds et al. 1995). When N. pruniforme is located on sedi- ments with fast mineralization rates, they may also benefit from nutrient release to the boundary layer overlying the sediment surfaces. However, the spherical form is still inefficient for light harvesting (Li \& Gao 2004). In addition, as a bottom-dwelling organism, $N$. pruniforme is highly sensitive to shading from phytoplankton and macroalgae, and we assume that the increase in nutrient loading of freshwaters observed almost worldwide is the main cause for the declining occurrence of this spectacular species.

Acknowledgements. This work was part of the CLEAR project (Centre for Lake Restoration) funded by the Villum Kann Rasmussen Foundation.

\section{LITERATURE CITED}

Allen ED, Spence DHN (1981) The differential ability of aquatic plants to utilize the inorganic carbon supply in freshwaters. New Phytol 87:269-283

Badger MR, Price GD (1992) The $\mathrm{CO}_{2}$ concentrating mechanism in cyanobacteria and microalgae. Physiol Plant 84: 606-615

- Badger MR, Price GD (2003) $\mathrm{CO}_{2}$ concentrating mechanisms in cyanobacteria: molecular components, their diversity and evolution. J Exp Bot 54:609-622

Beer S, Spencer W, Holbrook G, Bowes G (1990) Gas exchange and carbon fixation properties of the mat-forming cyanophyte Lyngbya birgei G. M. Smith. Aquat Bot 38: 221-230

Dodds WK (1989) Photosynthesis of two morphologies of Nostoc parmelioides (cyanobacteria) as related to current velocities and diffusion patterns. J Phycol 25:258-262

> Dodds WK, Castenholz RW (1988) Effects of grazing and light on the growth of Nostoc pruniforme. Br Phycol J 23: $219-227$

> Dodds WK, Gudder DA, Mollenhauer D (1995) The ecology of Nostoc. J Phycol 31:2-18

Finlay JC (2004) Patterns of lotic algal stable carbon isotope ratios. Limnol Oceanogr 49:850-861

Goericke R, Montoya JP, Fry B (1994) Physiology of isotopic fractionation in algae and cyanobacteria. In: Lajtha $\mathrm{K}$, Michener R (eds) Stable isotopes in ecology and environmental science. Blackwell, Oxford, p 187-221

Kaplan A, Badger MR, Berry JA (1980) Photosynthesis and the intracellular inorganic carbon pool in the bluegreen alga Anabaena variabilis: response to external $\mathrm{CO}_{2}$ concentration. Planta 149:219-226

Li Y, Gao K (2004) Photosynthetic physiology and growth as a function of colony size in the cyanobacterium Nostoc sphaeroides. Eur J Phycol 39:9-15

Littler MM, Littler DS (1980) The evolution of thallus form and survival strategies in benthic marine macroalgae: field and laboratory tests of a functional form model. Am Nat 116: $25-44$

Maberly SC, Spence DHN (1983) Photosynthetic inorganic carbon use by freshwater plants. J Ecol 71:705-724

Mackereth FJH, Heron J, Talling JF (1978) Water analyses. Scientific Publ. No. 36, Freshwater Biological Association, Ambleside

Madsen TV, Sand-Jensen K (1991) Photosynthetic carbon assimilation in aquatic macrophytes. Aquat Bot 41:5-40

Price GD, Coleman JR, Badger MR (1992) Association of car- 
bonic anhydrase activity with carboxysomes isolated from the cyanobacterium Synechococcus PCC7942. Plant Physiol 100:784-793

Qiu BS, Liu JY (2004) Utilization of inorganic carbon in the edible cyanobacterium Ge-Xian-Mi (Nostoc) and its role in alleviating photo-inhibition. Plant Cell Environ 27: 1447-1458

Raun AL, Sand-Jensen K, Borum J (2008) Mærkelige frugter i søerne. Urt 32.3:109-114

Raven JA, Kübler JE (2002) New light on the scaling of metabolic rate with the size of algae. J Phycol 38:11-16

Stumm W, Morgan JJ (1970) Aquatic chemistry. An introduc-

Editorial responsibility: Michael Kühl,

Helsingør, Denmark tion emphasizing chemical equilibria in natural waters. Wiley-Interscience, New York

Sültemeyer D, Klughammer B, Badger MR, Price GD (1998) Fast induction of high-affinity $\mathrm{HCO}_{3}{ }^{-}$transport in cyanobacteria. Plant Physiol 116:183-192

Volokita M, Zenvirth D, Kaplan A, Reinhold L (1984) Nature of the inorganic carbon species actively taken up by the cyanobacterium Anabaena variabilis. Plant Physiol 76: 599-602

Wintermans JFGM, DeMots A (1965) Spectrophotometric characteristics of chlorophylls $a$ and $b$ and their pheophytins in ethanol. Biochim Biophys Acta 109:448-453

Submitted: August 5, 2008; Accepted: December 4, 2008

Proofs received from author(s): January 23, 2009 